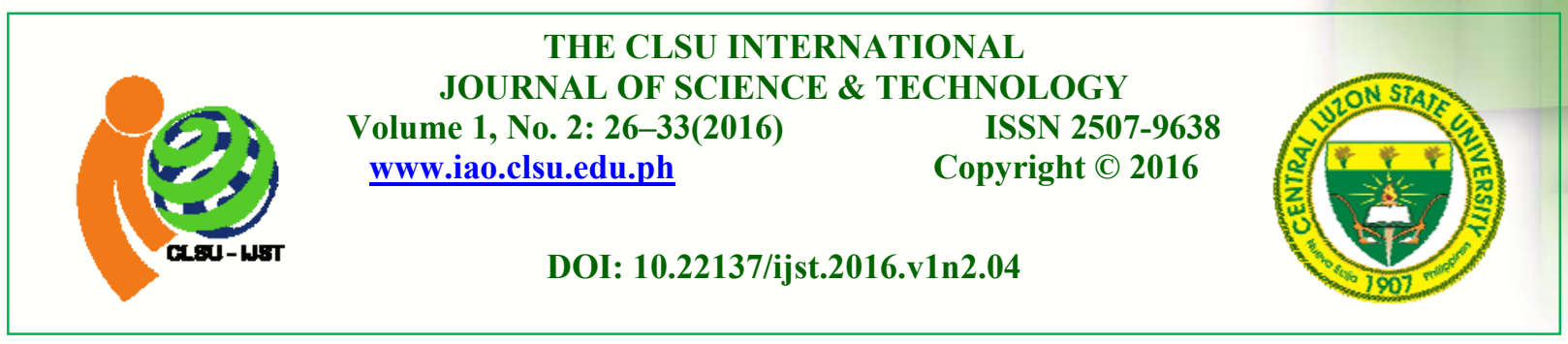

\title{
Development of a Vertical Disc Push-Type Double-Row Carrot Seeder for Small-Scale Farmers
}

\author{
Marvin T. Valentin \\ Department of Agricultural and Biosystems Engineering, College of Engineering, Central Luzon \\ State University, Science City of Munoz, Nueva Ecija, Philippines \\ Email for correspondence: m_valentin14@yahoo.com \\ Submitted 27 October 2016, Accepted 12 November 2016, Published online 31 December 2016
}

\begin{abstract}
This study was conducted to develop a push-type double-row carrot seeder. Specifically the study investigated the performance of the carrot seeder at different operating speeds in terms of field efficiency, field capacity, germination, and uniformity of seed discharge. In addition, the study aimed to establish optimum operating speeds and compare the use of the device and manual sowing of carrot seeds. The device consists of a hopper, seed metering disc, soil opener, and seed coverer, grip handle, ground wheel, and power transmission; all attached to the frame. The metering disc is synchronized with the ground wheel as a source of power during operation.

The design of the carrot seeder was prepared using AutoCAD software. It was fabricated using locally available materials. Three operating speeds $(0.75,1.0$, and $1.25 \mathrm{~m} / \mathrm{s})$ were used during the evaluation. An area of $225 \mathrm{sq}$. $\mathrm{m}$ was used. It was divided into 9 plots with dimension of $50 \mathrm{~cm}$ by $500 \mathrm{~cm}$. These plots accommodated the operating speeds with three replications.

Results of evaluation showed that the performance of the newly developed carrot seeder was optimum at a forward speed of $1.0 \mathrm{~m} / \mathrm{s}$ with a dropping efficiency of $96.7 \%$, coefficient of variation of $1.7 \%$, field efficiency of $88.2 \%$, germination of $82.3 \%$, and average number of seeds deposited of 2.5. The device was also found to be $76 \%$ faster than the conventional method of planting carrot seeds. For further improvement of the capacity of the device, an additional metering disc can be used.
\end{abstract}

Key words: carrot seeder, fabrication, field capacity, field efficiency, evaluation

\section{INTRODUCTION}

The level of mechanization of agriculture in the Philippines has progressed very little since 1990 with $0.52 \mathrm{hp} / \mathrm{hac}$ to $1.23 \mathrm{hp} / \mathrm{ha}$ in 2013 as reported by the Philippine Center for Postharvest Development and Mechanization. This figure indicates that the Philippines is far behind compared to neighboring countries in Asia like Japan with $7 \mathrm{hp} / \mathrm{ha}$, South Korea with $4.11 \mathrm{hp} / \mathrm{ha}$, and China 
with $4.10 \mathrm{hp} / \mathrm{ha}$. In addition, the mechanization level signifies that humans and animals are manually doing many farm tasks. This is evident in the high lands where small-scale farmers are manually performing most of the tasks in the field, such as land preparation, plant establishment, and harvesting. Although there are available machines in the country, these are mainly for the lowlands and for rice and corn production. Imported machines are also not compatible in the high lands because of several factors such as topography and land area. Among the farm operations in the highlands, planting/transplanting of vegetables, legumes, and root crops is identified to have a low level of mechanization (PCARRD 2009).

Carrot production in the Philippines is distributed over provinces of Benguet, Mountain Province, Ifugao, Nueva Vizcaya, Cebu, Davao del Sur, Negros Oriental, and Bukidnon. From these producing provinces, $78 \%$ of production comes from Benguet, Mountain Province and Ifugao (Cordillera regions). As of now, local farmers are still planting carrot seeds manually with a wooden puncher to make holes on the plant bed. The seeds are then dropped into the holes and then covered with soil. Usually, farmers hold plastic bowls containing seeds and pick the seeds with the thumb and index finger and then place the seeds into the holes. These farmers accomplish this in a bent position. After the seeds are deposited, another person will pass through the same beds to cover the seeds usually with a soft broom.

In the farm, a good harvest is ensured beginning with good germination of the planting materials. Good plant germination starts from sowing the right amount of seeds at the right depth and interval. Carrot is one of the Philippines'high-value crops. However, to raise carrots is a complicated task. Plot preparation alone requires significant effort. Farmer need to thoroughly prepare the soil by removing all large particles such as stones because it affects the size of the carrot roots during the development stage. Among other operations, the sowing of the seeds into the plant bed is more intense, since the recommended number of seeds in each hill should be followed to avoid seed wastage and economic loss. This requirement is difficult to attain as farmers get tired during the planting operation, causing them to sow seeds beyond the recommended one. Throughout the operation, farmers experience muscle fatigue causing them to sow inconsistent amounts of seeds.

Mechanizing farm operation like developing a multi-crop seeder may reduce losses in planting materials. At the same time, the amount of time the farmers usually spend in manual sowing can be dedicated to other important tasks in the field.

At the moment, no commercial carrot seeder is available for farmers. In other countries, the available seeders are usually mounted in tractors and built for large-scale farming. These seeders are not readily applicable to local conditions because of several factors such as land area, topography, and climatic condition. Thus, farmers in the highlands are still manually sowing carrot seeds. Hence ${ }_{2}$ this study was conducted to develop a carrot seeder suited under local conditions.

\section{MATERIALS AND METHODS}

\section{Design Features}

The carrot seeder was initially designed using AutoCAD software as shown in Figure 1. It has two metering discs, $20 \mathrm{~cm}$ in diameter. The disc has four cells around the circumference. A hole was bored in each cell to contain the carrot seed. The hole has a diameter of $5.0 \mathrm{~mm}$ and a depth of $5.0 \mathrm{~mm}$. The discs are held by a shafting with a diameter of $10.0 \mathrm{~mm}$ in the center. The shafting has a 13-tooth sprocket, connected by a chain to another sprocket of the same size attached to the axle of the ground wheel. The ground wheel is $40 \mathrm{~cm}$ in diameter and it serves as a power source for the metering disc to rotate.

Vol. 1 No. 2 (December 2016), ISSN: 2507-9638, DOI: 10.22137/ijst.2016.v1n2.04 


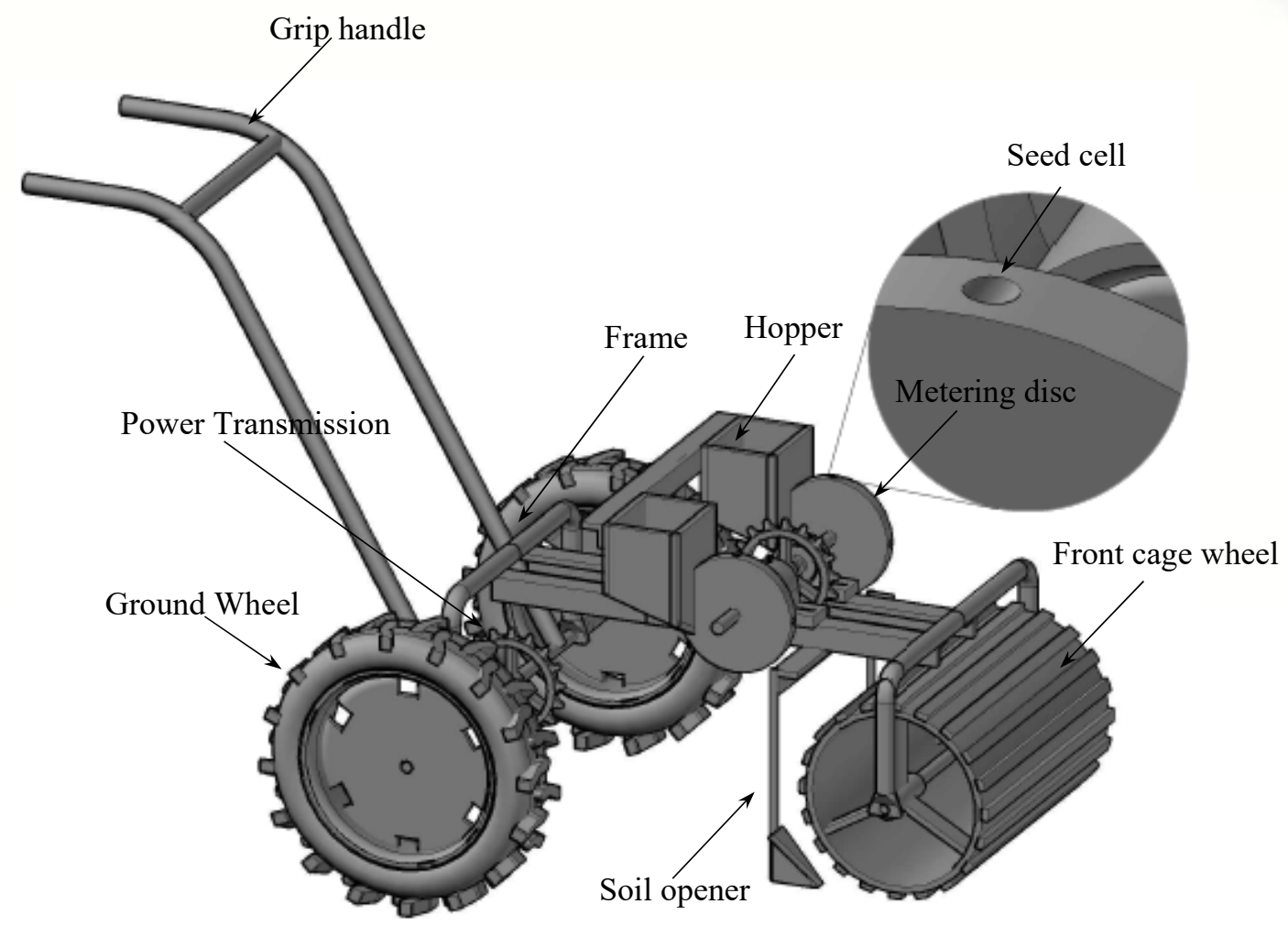

Figure 1. Isometric view of the carrot seeder

Table 1. Technical specifications of the carrot seeder

\begin{tabular}{cc}
\hline & Technical features \\
\hline \hline No. of metering disc & 2, made of fiber glass \\
Cells per disc plate & 4 cells, $1 / 4{ }^{\prime}$ \\
Hill spacing & 5 inches \\
Ground wheel & 2,18 inches diameter \\
Front wheel & Corrugated \\
Overall height & 3.5 feet \\
Overall width & 18 inches \\
\hline \hline
\end{tabular}

\section{Special features}

Handle is adjustable

The distance between the metering disc is adjustable to vary row spacing

Sprocket can be replaced to vary hill spacing

\section{Test Material}

A $50.0 \mathrm{~g}$ sack of Tokita carrot seeds was prepared for the evaluation. It contained a total of 2000 seeds. Each seed is approximately 0.025 grams. The seed had a label of $80 \%$ germination.

\section{Test Area and Evaluation}

The evaluation of the carrot seeder was patterned to the specifications provided in the Philippine Agricultural Engineering Standards for seeder and planter. A test area with a dimension of $450 \mathrm{~cm}$ by 5000 $\mathrm{cm}$, was thoroughly prepared for the evaluation. It was divided into 9 plots to accommodate 9 tests from the 
three operating speeds at three replications as shown in Figure 2. Each plot corresponds to one test and had measurements of $50 \mathrm{~cm}$ width and $5000 \mathrm{~cm}$ in length. Straight lines were drawn to separate each plot and served as guide during the evaluation. The evaluation proper was carried out through the following activities:

1. The carrot seeds were loaded to the hopper of the carrot seeder;

2. The seeder was operated at a forward speed of $1.0 \mathrm{~m} / \mathrm{s}$ on the first plot. The drag chain was not used at this time but was utilized for the second and third plots;

3. The duration of planting the first three plots was recorded including the time of maneuvering. Time measurement was in seconds;

4. On the first plot, the seed deposited to each hill was counted and recorded including the total number of hills;

5. After accounting the seeds, the carrot seeder was operated at the same speed over the plot but the power transmission to the metering disc was disengaged to avoid deposition of seeds. The drag chain of the seeder was used to cover the seeds;

6. After evaluating the $1.0 \mathrm{~m} / \mathrm{s}$, it was succeeded with the evaluation of the device using $1.5 \mathrm{~m} / \mathrm{s}$ forward speed over another 3 plots following the same procedure as that with $1.0 \mathrm{~m} / \mathrm{s}$. The same procedure was implemented to $2.0 \mathrm{~m} / \mathrm{s}$ for the remaining 3 plots;

1.7. The remaining seeds after the evaluation were also recorded.

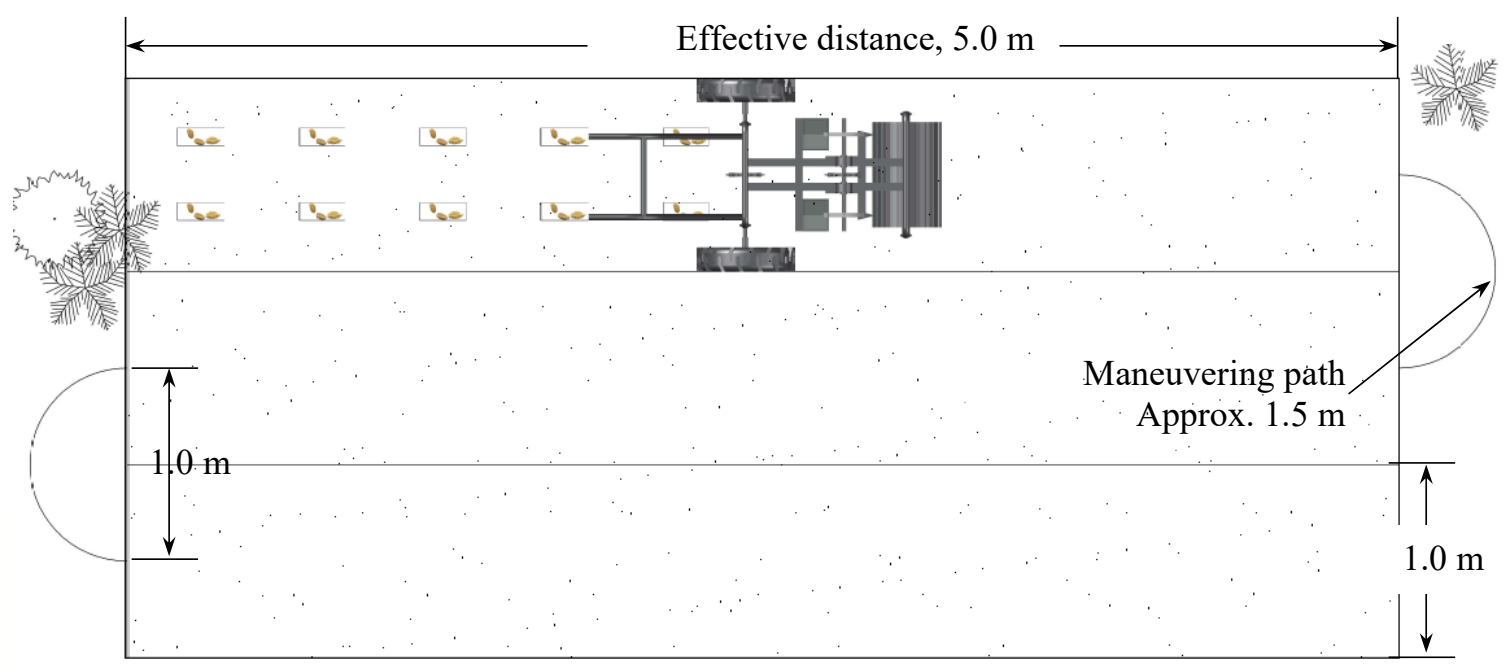

Figure 2. Field layout

\section{Statistical Tools}

Data were analyzed using Complete Randomized Design with operating speeds as treatment. Differences among the means were further analyzed using Duncan's Multiple Range Test at $5 \%$ level of significance.

\section{Evaluation Parameters}

Machine parameters included three different operating speeds, $0.75 \mathrm{~m} / \mathrm{s}, 1.0 \mathrm{~m} / \mathrm{s}_{2}$ and $1.25 \mathrm{~m} / \mathrm{s}$. While the performance criteria of the machine was indicated by the dropping efficiency, coefficient of variation of the discharged seed, percent germination, field efficiency, and field capacity. 
The dropping efficiency is the ratio of the number of missed hills to the total number of hills the seeder should deposit seeds. This is shown in Equation 1, where of $f$ stands for the dropping efficiency in percent.

$$
\text { คff }
$$

The coefficient of variation of the discharged seeds indicates how uniform were the number of seeds dropped from hill to hill. This was determined using Equation 2 and Equation 3 where $c V$ stands for coefficient of variation, and $S D$ for standard deviation.

$$
S D-\sqrt{\frac{C V=\frac{S D}{M E x^{2}-\sum x^{2}}}{n(n-1)}} \times 100
$$

Percent germination in each hill is the ratio of the number of seeds that emerged to the total number of seeds sown. This is given by Equation 4 .

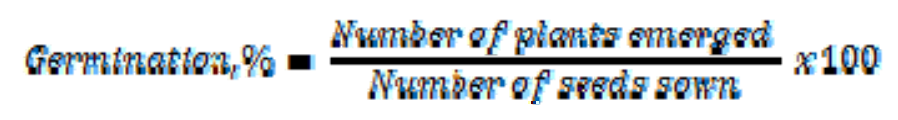

Field capacity is the measure of how fast the carrot seeder plants. It is expressed in units of hac per $\mathrm{hr}(\mathrm{hac} / \mathrm{hr}$ ). Field capacity is either theoretical or actual. The theoretical capacity is simply the ratio of the area to the theoretical time the seeder would take to completely sow the given area. Actual field capacity is the ratio of the actual area to the actual time elapsed in operating the seeder over the area.

Field efficiency is the function of the time consumed during the actual evaluation and the theoretical time. Aside from time, it can be determined by taking the ratio of the actual and theoretical field capacity. Mathematically, field efficiency was determined using Equation 5. Where $t_{t h}$ is the theoretical time and efff is field efficiency in percent.

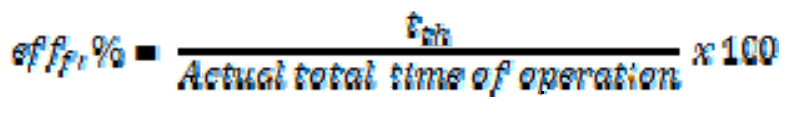

Theoretical time would mean the computed time of operation over the effective distance without considering losses in the field such as the time in maneuvering between the plant beds. The effective distance corresponds to the length of the field at which the seeder can only sow seeds while operating. In this study, it was $15.0 \mathrm{~m}$ at $5.0 \mathrm{~m}$ for each plot. Thus theoretical time $\left(t_{\mathrm{th}}\right)$ is the ratio of the effective distance (15.0) and the forward operating (FOS) speed in kph as expressed by Equation 6.

$$
t_{\mathrm{th}}=\frac{\mathrm{gA}}{\mathrm{spagd}}
$$




\section{RESULTS AND DISCUSSION}

\section{Machine Performance}

Table 2 shows the performance of the carrot seeder as indicated by the averages on dropping efficiency, coefficient of variation and percent germination. Data from manual sowing of the carrots are also presented for comparison.

Table 2. Performance of the carrot seeder

\begin{tabular}{ccccc}
\hline Operating speed (m/s) & $\begin{array}{c}\text { Dropping } \\
\text { efficiency, \% }\end{array}$ & $\begin{array}{c}\text { Average seeds } \\
\text { dropped }\end{array}$ & $\begin{array}{c}\text { Coefficient of } \\
\text { variation, \% }\end{array}$ & $\begin{array}{c}\text { Percent } \\
\text { germination,\% }\end{array}$ \\
\hline \hline 0.75 & $97.1^{\mathrm{a}}$ & $3.2^{\mathrm{b}}$ & $1.5^{\mathrm{a}}$ & $82.8^{\mathrm{a}}$ \\
1.0 & $96.7^{\mathrm{a}}$ & $2.5^{\mathrm{a}}$ & $1.7^{\mathrm{a}}$ & $82.3^{\mathrm{a}}$ \\
1.25 & $96.3^{\mathrm{a}}$ & $2.3^{\mathrm{a}}$ & $2.8^{\mathrm{b}}$ & $81.7^{\mathrm{a}}$ \\
Manual sowing & $99.3^{\mathrm{b}}$ & $7.3^{\mathrm{c}}$ & $3.5^{\mathrm{c}}$ & $82.1^{\mathrm{a}}$ \\
\hline
\end{tabular}

\section{Dropping Efficiency}

The dropping efficiency of the device shows an inverse relationship with the forward operating speed with highest dropping efficiency of $97.1 \%$ observed at lowest speed $0.75 \mathrm{~m} / \mathrm{s}$, compared to the fastest forward speed of $1.25 \mathrm{~m} / \mathrm{s}$ with a dropping efficiency of $96.3 \%$. The high speed of the device gives a quick rotation of the metering disc. This causes insufficient time for the seeds to be loaded in the cell of the metering disc. On the other hand, at lower speed, the metering disc rotates slowly allowing more time for the metering disc to interact with the seeds in the hopper as it rotates, having a greater chance to load all the cells with seeds. Nonetheless, in terms of dropping efficiency, the difference among three operating speeds were found to be statistically insignificant at $5 \%$ level of significance. This suggests that the farmers can use any of the speeds within the range to correspond with their normal walking speed. However, manual sowing was significantly higher in dropping efficiency among the three operating speeds.

\section{Uniformity of Discharge}

The recommended number of seeds in each hill is 2 to 5 seeds, though only one plant is needed. This is to account the viability of the seeds in the soil as indicated by the germination rate and the possible damage or loss of plant caused by pests and heavy rain. On the average, the three operating forward speeds during the evaluation were found to deposit seeds within the recommended range. The highest average is 3.2 seeds observed at a speed of $0.75 \mathrm{~m} / \mathrm{s}$. This is possibly the result of dropping efficiency where only around $2.9 \%$ of the total hills were missed. Higher forward speed had more number of hills missed that affected the average dropped seeds.

The number of seeds deposited in each hill was found to be more uniform using $0.75 \mathrm{~m} / \mathrm{s}$ as indicated by the coefficient of variation of $1.5 \%$ and is statistically insignificant to $1.7 \%$ at $1.0 \mathrm{~m} / \mathrm{s}$. This indicates that each hill using a speed of 0.75 and $1.0 \mathrm{~m} / \mathrm{s}$ dropped more or less uniform seeds that varies from 1.5 to $1.7 \%$ on the average. Compared to $1.25 \mathrm{~m} / \mathrm{s}$ where variation was highest, $2.8 \%$. This high variation indicates that the average number of seeds among the hills has a bigger difference and they are not uniform.

\section{Germination}

As recorded, the germination at the three speeds including those manually sown is statistically insignificant. As indicated, the germination of the seeds that was used is $80 \%$ which was exceeded during the actual evaluation ranging from 1.7 to $2.8 \%$. 


\section{Field Efficiency}

The expression of how efficient the carrot seeder was during the actual operation as compared to the expected length of operation is given as field efficiency. Table 3 shows the recorded actual time of operation along the effective length and the maneuvering path and the corresponding computed or theoretical time. It also shows the calculated capacity and field efficiency.

Table 3. Field efficiency and capacity of the carrot seeder.

\begin{tabular}{|c|c|c|c|c|c|c|c|c|c|c|c|c|}
\hline \multirow{3}{*}{$\begin{array}{c}\text { Operating } \\
\text { speed } \\
\mathrm{m} / \mathrm{s}\end{array}$} & \multirow{2}{*}{\multicolumn{6}{|c|}{ Time (seconds) }} & \multirow{2}{*}{\multicolumn{3}{|c|}{ Time loss, \% (computed) }} & \multirow{2}{*}{\multicolumn{2}{|c|}{ Capacity, hac/hr }} & \multirow{3}{*}{$\begin{array}{c}\text { Field efficiency, } \\
\%\end{array}$} \\
\hline & & & & & & & & & & & & \\
\hline & Effective & Maneuvering & Total & Effective & Maneuvering & Total & Effective & Maneuvering & Overall & Theoretical & Actual & \\
\hline 0.75 & 23 & 4.5 & 27.5 & 20 & 4 & 24 & 15.0 & 12.5 & 14.6 & 0.121 & 0.105 & $87.0^{\mathrm{b}}$ \\
\hline 1.0 & 17 & 3.8 & 20.8 & 15 & 3 & 18 & 13.3 & 26.7 & 15.6 & 0.162 & 0.142 & $88.2^{\mathrm{c}}$ \\
\hline 1.25 & 14 & 2.9 & 16.9 & 12 & 2.4 & 14.4 & 16.7 & 20.8 & 17.4 & 0.202 & 0.173 & $85.7^{\mathrm{a}}$ \\
\hline
\end{tabular}

The actual total time of sowing the seeds is comprised of the effective time and maneuvering. The effective time is the duration in operating the seeder over the effective distance which is the length of the plot as shown in Figure 2. In this study, effective distance was $15.0 \mathrm{~m}$ for the 3 plots at $5.0 \mathrm{~m}$ each. Maneuvering time is the duration of transferring the seeder to the next plot including positioning. On the other hand, theoretical or expected time based on the operating speed and the distance also corresponds to effective time over the effective distance and the maneuvering time at the end of the plots. A more interesting parameter combining these times is the time loss which indicates the percentage of the time that is lost with reference to the theoretical time. At a speed of $1.25 \mathrm{~m} / \mathrm{s}$, the time loss is $16.7 \%$ for the effective distance.

Another effective time on the basis of theoretical operation shows lower values than the actual and they are lower compared to the total operating time. From this data, it is clear that the gap is highly affected by the maneuvering time.

The use of $1.0 \mathrm{~m} / \mathrm{s}$ forward speed resulted to the highest field efficiency of $88.2 \%$. Contrary to this result, as expected $1.25 \mathrm{~m} / \mathrm{s}$ should have given the highest efficiency since it is faster than the other speeds, and therefore lesser time is consumed. However, the theoretical time for the $1.25 \mathrm{~m} / \mathrm{s}$ to operate over the 3 plots (15.0 m effective length) was not the same with the actual effective time. Theoretically it should be completed in at least 14.4 seconds, but it took around 16.9 seconds to complete the operation. In addition, the highest time loss computed was $17.4 \%$ which was observed at a speed of $1.25 \mathrm{~m} / \mathrm{s}$. Compared to $1.0 \mathrm{~m} / \mathrm{s}$ where time loss was only $15.6 \%$. These findings indicate that faster speed does not mean a shorter period of time to complete sowing of carrot seeds. Instead, it deals with which compatible operating speed the carrot seeder should be operated to smoothly finish sowing operation. At $1.25 \mathrm{~m} / \mathrm{s}$, the seeder was observed to slide making the operator stop for a while. Investigation of the sliding of the machine revealed that that there was not enough lubricant on the bearing of the ground wheel making it difficult to rotate at a faster speed, thereby causing the seeder to slide. Compared to the other two speeds where the time delay is significantly lower. Nonetheless, the efficiency of the seeder is higher compared to other locally fabricated seeders. For instance, the jab seeder that was developed by Braide and Njidda in 1989 had an efficiency of $73.4 \%$. In 2014 , Olajide also designed a local type that was $71 \%$ efficient.

\section{Conclusions}

A push-type double row carrot seeder was designed, fabricated, and evaluated. Three operating speeds $(0.75,1.0$, and $1.25 \mathrm{~m} / \mathrm{s})$ were used during the evaluation over an area of $450 \mathrm{~cm}$ by $5000 \mathrm{~cm}$. Results revealed that the seeder had an optimum performance when operated at $1.0 \mathrm{~m} / \mathrm{s}$ with a dropping efficiency of $96.7 \%$, coefficient of variation of $1.7 \%$, field efficiency of $88.2 \%$, germination of $82.3 \%$, and average

Vol. 1 No. 2 (December 2016), ISSN: 2507-9638, DOI: 10.22137/ijst.2016.v1n2.04 
number of seeds deposited of 2.5. Comparison between the use of the seeder and the manual sowing was also done. The device was also found to be $76 \%$ faster than the conventional method of planting carrot seeds.

\section{Recommendations}

To improve the capacity of the device, the use of additional metering disc may be considered. The capacity of $0.142 \mathrm{hac} / \mathrm{hr}$ is high compared to some other seeder designs, such as Hoque (2013) design with $0.08 \mathrm{hac} / \mathrm{hr}$.

\section{REFERENCES}

Hoque, M.A. and M.A. Wohab. 2013. "Development and Evaluation of a Drum Seeder for Onion." International Journal of Agricultural Research, Innovation, and Technology 3 (1): 26-28. http://www.ijarit.webs.com

Olajide, O.G. and S.I. Manuwa. 2014. "Design, Fabrication, and Testing of a Low-cost Row-Crop Planter for Peasant Farmers." Proceedings of the International Soil Tillage Research Organisation (ISTRO) Nigeria Symposium, November 3 - 6. Akure, Nigeria: ISTRO.

PAES 122:2001. Philippine Agricultural Engineering Standards. Agricultural Machinery -Seeder and Planter-Specifications.

PAES 122:2001. Philippine Agricultural Engineering Standards. Agricultural Machinery -Seeder and Planter-Methods of Test.

Valentin, M.T. and J.J.F. Malamug. 2012. "Design, Fabrication, and Performance Evaluation of a Single-Row Carrot Seeder.” BS thesis, Benguet State University. 